\title{
Influence of Thermal Treatment on Mechanical and Morphological Characteristics of Polyamide 11/Cellulose Nanofiber Nanocomposites
}

\author{
Denis Mihaela Panaitescu, ${ }^{1}$ Raluca Augusta Gabor, ${ }^{1}$ \\ Adriana Nicoleta Frone, ${ }^{1}$ and Eugeniu Vasile ${ }^{2}$ \\ ${ }^{1}$ Polymer Department, National Institute for Research and Development in Chemistry and Petrochemistry, \\ 202 Splaiul Independentei, 060021 Bucharest, Romania \\ ${ }^{2}$ Faculty of Applied Chemistry and Material Science, University Politehnica of Bucharest, 1-7 Gh. Polizu Street, \\ 011061 Bucharest, Romania
}

Correspondence should be addressed to Denis Mihaela Panaitescu; panaitescu@icf.ro and Raluca Augusta Gabor; ralucagabor@yahoo.com

Received 19 November 2014; Accepted 23 January 2015

Academic Editor: Yibing Cai

Copyright (C) 2015 Denis Mihaela Panaitescu et al. This is an open access article distributed under the Creative Commons Attribution License, which permits unrestricted use, distribution, and reproduction in any medium, provided the original work is properly cited.

\begin{abstract}
Nanocomposite films were prepared from polyamide 11 (PA11) and cellulose nanofibers (CN) by melt compounding and compression molding. The impact of thermal treatment on the morphology and mechanical behavior of PA11 and nanocomposite films was studied using dynamic mechanical analysis, tensile tests, X-ray diffraction (XRD), and peak force (PF) QNM technique. Slightly higher storage modulus values were obtained for nanocomposites compared to the matrix before the treatment, but a noticeable increase was observed after the treatment. Although $\mathrm{CN}$ addition determined increased tensile strength and modulus both before and after the treatment, the increase was much more significant in the case of treated films. The best mechanical properties were shown by treated PAll films containing $5 \mathrm{wt} \% \mathrm{CN}$, with $40 \%$ higher Young's modulus and with $35 \%$ higher tensile strength compared to the matrix. Some of the changes pointed out by static and dynamic mechanical tests were explained by the morphological changes determined by the thermal treatment and emphasized by PF QNM and by the increase of XRD crystallinity. A transition from lamellar stack morphology to one involving spherulites was highlighted by AFM. Thermal treatment has proved a valuable method for improving the mechanical properties of PA11/CN composites.
\end{abstract}

In memoriam of Dr. Constantin Radovici who died in March 2014

\section{Introduction}

Promotion of environmental protection has determined intensive research to develop high performance materials by the exploitation of renewable resources [1-6]. Bio-based polyamides are increasingly studied as solution to the fast depletion of fossil reserves and increased greenhouse gas emission. Prepared starting from castor beans, polyamide 11 (PA11) is a valuable engineering polymer characterized by wide working temperatures, good dimensional stability, and excellent chemical resistance. Moreover, PA11 has low carbon footprint due to the locked atmospheric carbon and can serve as solution in climate change mitigation strategies. Some effort has been devoted to the enhancement of the mechanical properties of PA11 by using different reinforcing agents [7-13]. Layered silicates and carbon nanotubes were mostly studied as nanofillers. Increased elastic modulus and yield strength were generally reported for nanocomposites compared to pristine PA11 $[9,11]$. Some decrease of thermal stability was reported for PA11 nanocomposites at clay concentrations 
higher than $4 \mathrm{wt} \%$ [7] and increased stability up to $10 \mathrm{wt} \%$ clay for PA11/clay nanocomposites prepared using a water-assisted extrusion route [8].

In an attempt for taking full advantage of nature potential, PA11 was modified by cellulose nanofibers (CN) [14]. Because of their renewability, biodegradability, and remarkable mechanical properties, $\mathrm{CN}$ were successfully tested for improving the mechanical properties of various polymers $[4,6,15-19]$. CN were tested as reinforcing fillers in both biobased $[4,6,16]$ and synthetic polymers [17-19]. Encouraging results were reported for polyamide 11 reinforced with $\mathrm{CN}$, an increase of both yield strength and elastic modulus being observed from 1 to $5 \mathrm{wt} \% \mathrm{CN}$ in nanocomposites [14]. Moreover, good thermal stability was found in all PA11/CN nanocomposites, the weight loss being less than $1 \%$ up to $270^{\circ} \mathrm{C}[14]$.

Flexible bio-based polymer films with good mechanical properties, thermal stability, and chemical resistance are increasingly required in the design of lightweight and flexible electronics and robotics as well as in automotive or packaging applications. PA11/CN nanocomposite films could bring together good properties and the green character.

Several studies were reported on the influence of annealing treatment on the structure of PA11 [20]. Annealing is usually applied as a crystallization technique, which accelerates the secondary crystallization process under the temperature of the maximum crystallization rate. Zhang et al. have found that there is an optimum annealing temperature for PA11, around $165^{\circ} \mathrm{C}$, when a maximum value of the degree of crystallinity is obtained [20].

In this paper, $\mathrm{CN}$ were prepared in dry form and dispersed in different proportion in PA11 by melt compounding. The films were obtained by compression molding and then annealed at $165^{\circ} \mathrm{C}$ for one hour. Dynamic mechanical analysis (DMA), XRD, tensile tests, and peak force QNM (quantitative nanomechanical mapping), an AFM technique, were used to quantify the influence of both $\mathrm{CN}$ and annealing on the morphology and mechanical properties of PA11 matrix.

\section{Materials and Methods}

2.1. Materials. Microcrystalline cellulose (MCC) with a mean particle size of $20 \mu \mathrm{m}$, purchased from Sigma Aldrich Co. (USA), and sulfuric acid $\left(\mathrm{H}_{2} \mathrm{SO}_{4}\right)$ 96\% from Chimopar (Romania) were used to prepare cellulose nanofibers. Polyamide 11 D60 powder was donated by Arkema (France).

2.2. Preparation of $\mathrm{CN}$ and Nanocomposites. $\mathrm{CN}$ were obtained by acid hydrolysis starting from MCC, as described elsewhere [14]. PA11 and CN were dried before melt compounding in a vacuum oven for $4 \mathrm{~h}$ at $80^{\circ} \mathrm{C}$ and $60^{\circ} \mathrm{C}$, respectively, in order to remove the absorbed water. $\mathrm{CN}$ (1, 3, 5, or $8 \mathrm{wt} \%$ ) were dispersed in PA11 using a Brabender Lab-Station (Germany) mixing chamber at a temperature of $185^{\circ} \mathrm{C}$ for $6 \mathrm{~min}$, the speed of the rotors of $100 \mathrm{rpm}$. The compounded mixtures were shaped in foils at $150^{\circ} \mathrm{C}$ using a laboratory two-roll mill from Brabender (Polymix 110L) with $27 / 22.5 \mathrm{rpm}$ rotors speed. Films of $20-30 \mu \mathrm{m}$ in thickness were obtained by compression molding using an electrically heated platen press (P200E from Dr. Collin, Germany) at $190^{\circ} \mathrm{C}, 3$ minutes preheating ( 5 bar), 2 minutes under pressure (150 bar), and cooling for another 2 minutes in a cooling cassette. Neat PA11 film was prepared in the same conditions and used as reference. The films were thermally treated at $165^{\circ} \mathrm{C}$ for one hour. The nanocomposites were denoted $\mathrm{PA} 11 / \mathrm{CN}$ followed by a number indicating the concentration of CN.

2.3. AFM Analysis of Cellulose Nanofibers and Nanocomposites. The size of $\mathrm{CN}$ was investigated in tapping mode using a MultiMode 8 from Bruker, USA, equipped with a Nanoscope $\mathrm{V}$ controller and silicon tip (nominal radius $8 \mathrm{~nm}$, cantilever length $225 \mu \mathrm{m}$, and resonance frequency $75 \mathrm{kHz}$ ). Freezedried $\mathrm{CN}$ were dispersed in deionized water and one drop was dripped on a glass plate and dried under vacuum for 24 hours at $30^{\circ} \mathrm{C}$ before AFM investigation.

PA11 and nanocomposites films (before and after treatment) were mapped at molecular scale using peak force (PF) QNM mode of MultiMode 8 AFM from Bruker (USA). PF QNM enables quantitative measurement of nanoscale properties by performing a very fast force-separation curve at every pixel in the image and using the peak force as feedback signal $[21,22]$. A silicon tip with the nominal radius of $8 \mathrm{~nm}$, cantilever length of $225 \mu \mathrm{m}$, and resonant frequency of $90 \mathrm{kHz}$ was used for these measurements.

2.4. Mechanical Characterization. Tensile properties were determined using Instron 3382 testing machine with video extensometer at room temperature with a crosshead speed of $2 \mathrm{~mm} / \mathrm{min}$. Five specimens, 5A type according to ISO 527, were stamped from the treated and untreated films and tested for each sample. Young's modulus was automated determined using Bluehill 2 software.

Dynamic mechanical analysis was performed in tensile loading mode using a DMA Q800, TA Instrument with heating rate of $3^{\circ} \mathrm{C} / \mathrm{min}$. Duplicate samples from both treated and untreated films, $12 \times 6.5 \times 0.03 \mathrm{~mm}$ (length $\times$ width $\times$ thickness), were scanned over a temperature range of 30$120^{\circ} \mathrm{C}$ under frequency of $1 \mathrm{~Hz}$. All samples were equilibrated at room temperature for $5 \mathrm{~min}$.

2.5. X-Ray Diffraction. XRD analysis of PA11 and nanocomposites (before and after the treatment) was performed on a PANalytical X'PERT PRO MPD diffractometer using $\mathrm{Cu}$ $\mathrm{K} \alpha$ radiation $(\lambda=0.15418 \mathrm{~nm})$, from $5^{\circ}$ to $40^{\circ} 2 \theta$ angle. The $d$-spacing was calculated using Bragg's law. Crystallinity was estimated by using the model of two-phase approach. Fitting the diffraction patterns with Gaussian and Lorentzian functions (Fityk software) was undertaken and the relative degree of crystallinity was determined by dividing the area under crystalline peaks to the total area, under crystalline peaks and amorphous part.

\section{Results and Discussion}

3.1. AFM Analysis of CN. AFM image of CN from Figure 1 shows both single and agglomerated needle-like fibers of 


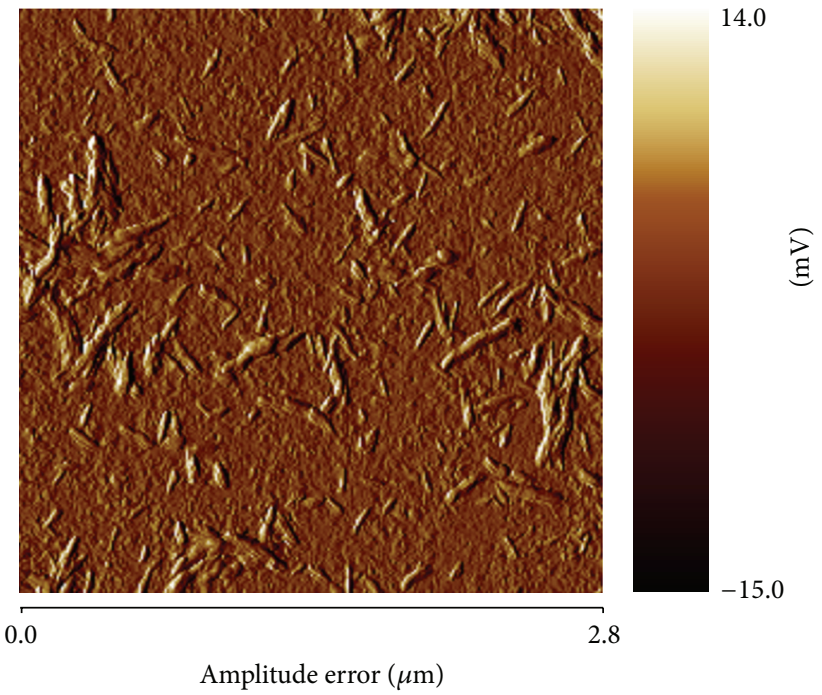

FIgURE 1: AFM image of cellulose nanofibers.

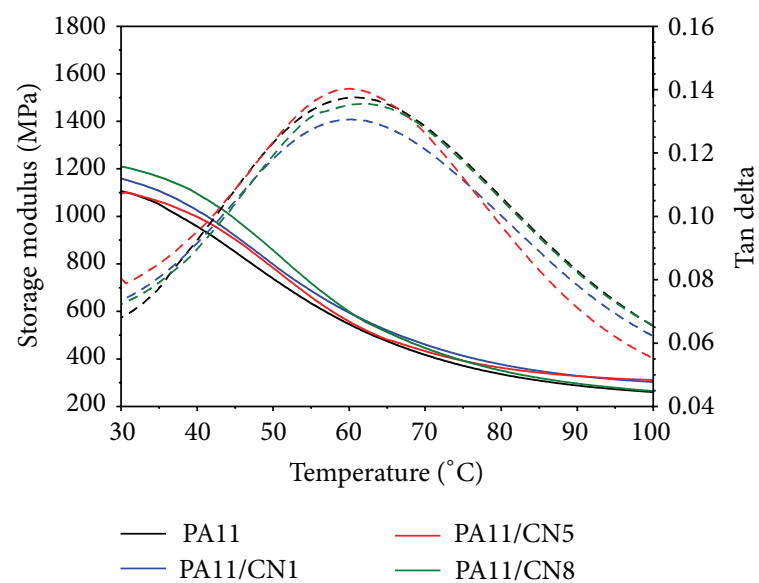

(a)

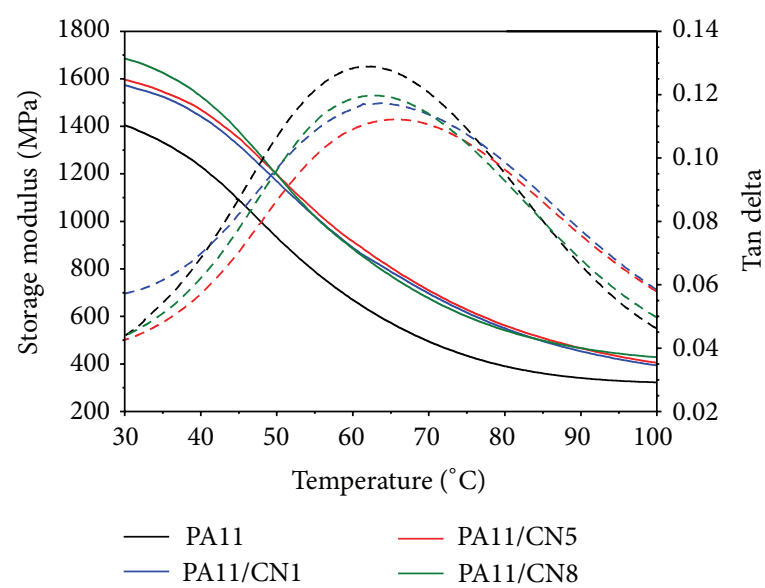

(b)

FIGURE 2: Storage modulus (solid lines) and $\tan \delta$ (dashed lines) of nanocomposites and PA11, before (a) and after (b) thermal treatment.

15 to $30 \mathrm{~nm}$ in thickness and 50 to $400 \mathrm{~nm}$ in length. The thickness of $\mathrm{CN}$ is in the range of other reported values for nanocellulose produced by acid hydrolysis $[6,23]$. The AFM image supports the nanometer size of the fibers and their large aspect ratio.

3.2. DMA Characterization. Storage modulus $\left(E^{\prime}\right)$ and $\tan \delta$ of the nanocomposites with different concentration of $\mathrm{CN}$ and PAll reference, before and after the thermal treatment, are shown in Figure 2.

Slightly higher $E^{\prime}$ values were obtained for nanocomposites compared to the matrix before the treatment, the increase being not proportional with the concentration of $\mathrm{CN}$ in composites (Figure 2(a)). The highest increase of $E^{\prime}$ at room temperature was observed for PA11/CN8, of about $10 \%$ compared to PA11. Glass transition temperature $\left(T_{g}\right)$, determined from $\tan \delta$ curves, was close to $61^{\circ} \mathrm{C}$ for all the samples, showing small influence of CN on the $T_{g}$ of PA11.

Different behavior was remarked after the treatment, a noticeable increase of storage modulus being observed for all the samples and visible difference between nanocomposites and neat PA11. The $E^{\prime}$ value was $1403 \mathrm{MPa}$ for the matrix, with $27 \%$ higher than before the treatment, $1595 \mathrm{MPa}$ for PA11/CN5, with $45 \%$ higher than the initial value, and $1684 \mathrm{MPa}$ for PA11/CN8, with $42 \%$ higher than before the treatment. After the treatment, the highest increase of $E^{\prime}$ at room temperature was found for PA11/CN8, of $20 \%$ relative to the matrix.

A decrease of the intensity of $\tan \delta$ peak was observed for nanocomposites compared to the matrix, the highest decrease being remarked in the case of PA11/CN5, which showed the highest rigidity. Higher $T_{g}$ values were obtained 


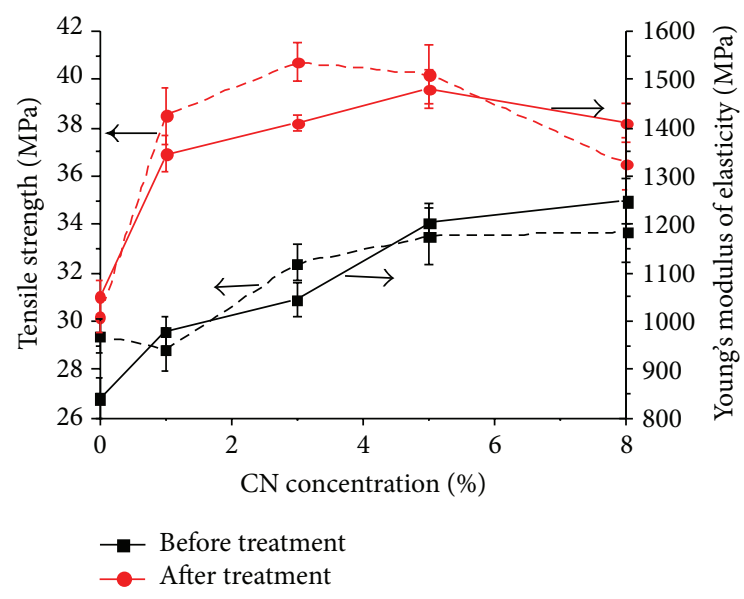

FIGURE 3: Tensile strength at break and Young's modulus of elasticity of PA11 and nanocomposites before (black lines) and after (red lines) thermal treatment.

for nanocomposites compared to neat PAll after the treatment, $65^{\circ} \mathrm{C}$ for PA11/CN1 and $66^{\circ} \mathrm{C}$ for PA11/CN5 compared to $62^{\circ} \mathrm{C}$ for the matrix. This is generally attributed to the restricted segmental motion at the interface and highlights strong interaction between $\mathrm{CN}$ and the matrix. Smaller increase of $T_{g}$ value was observed for PA11/CN8 probably because of $\mathrm{CN}$ agglomerates.

3.3. Mechanical Properties. Tensile strength and Young's modulus of elasticity of PA11 and nanocomposites before the thermal treatment are shown in Figure 3 (black lines). A relatively steady increase of Young's modulus was observed, from $840 \mathrm{MPa}$ for neat PAll to $1250 \mathrm{MPa}$ for the composite with $8 \mathrm{wt} \% \mathrm{CN}$ and a small increase of tensile strength, from 29.4 MPa to 33.7 MPa for PA11/CN8 compared to PA1l. However, the effect of $\mathrm{CN}$ on the mechanical properties of PAll is smaller for high concentration (Figure 3).

The efficiency of $\mathrm{CN}$ in improving the strength and stiffness of PA11 is much more pronounced after the thermal treatment. This could result from the morphological changes induced by the treatment and $\mathrm{CN}$ addition. It is known that the thermal treatment favors secondary crystallization leading to lamellar structures with lower melting point and enhancing the rearrangement of the molecular chains in more ordered structures [20]. Hence, higher crystallinity and higher crystal perfection are expected after the treatment. However, the presence of $\mathrm{CN}$ could induce additional changes depending on their content in the composites which may interfere with the treatment. Therefore, PA1l and nanocomposite films were investigated by XRD and AFM to point out the morphological changes caused by the treatment and $\mathrm{CN}$ and the results were shown in the next sections.

A significant increase of both tensile strength and modulus was observed for $1-3 \mathrm{wt} \% \mathrm{CN}$ in composites, with $27-28 \%$ for PA11/CN1 and $34-35 \%$ for PA11/CN3. Higher content than $5 \mathrm{wt} \% \mathrm{CN}$ is less efficient and a decrease of mechanical properties was detected for PA11/CN8 compared to PA11/CN5. The best mechanical properties were shown by

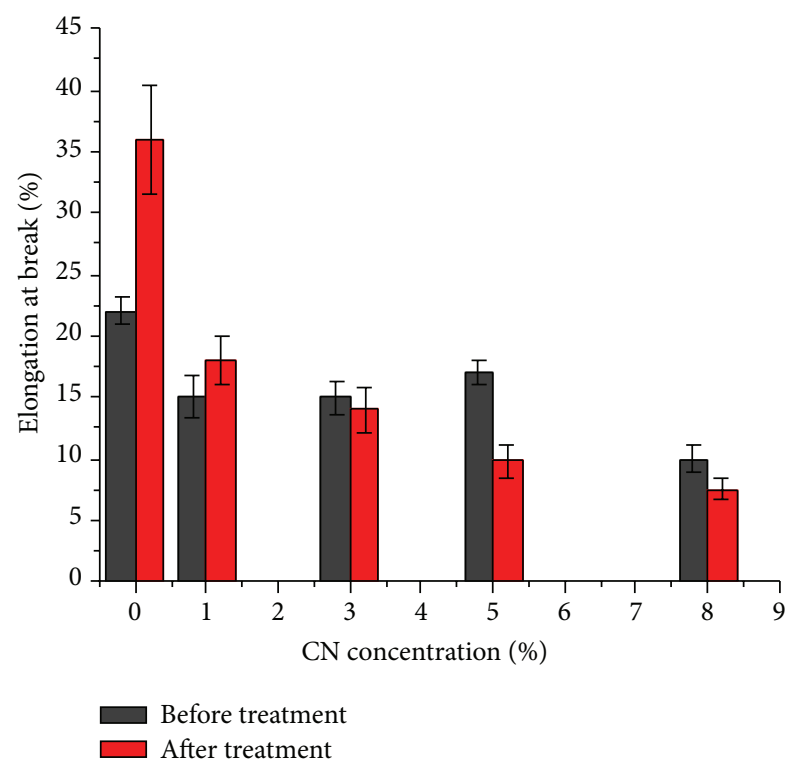

FIgURE 4: Elongation at break versus CN concentration.

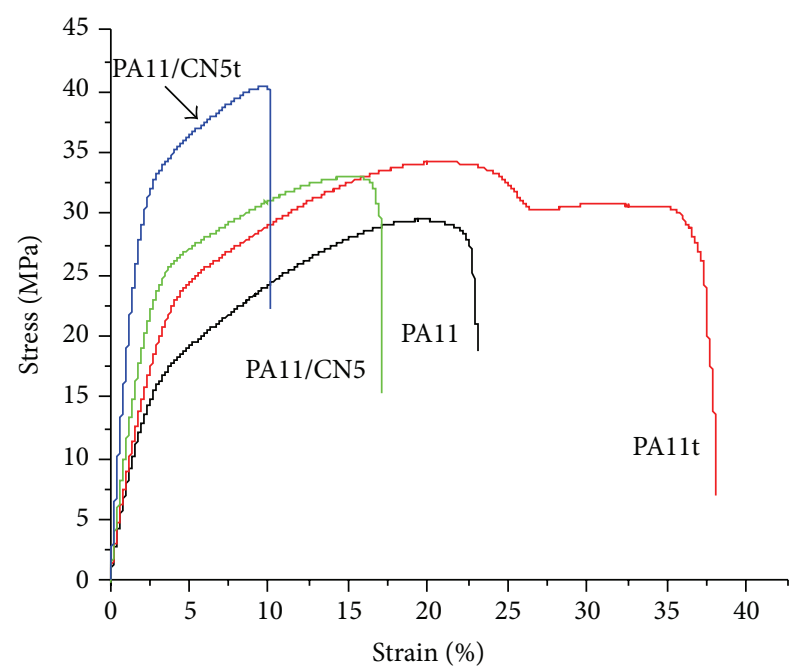

FIGURE 5: Stress-strain curves of the reference and composite with $5 \mathrm{wt} \% \mathrm{CN}$, before and after the thermal treatment.

treated PA11/CN5, an increase of Young's modulus with more than $40 \%$ and of tensile strength with $35 \%$ compared to the matrix being obtained. These results are consistent with DMA observations.

Elongation at break was smaller after $\mathrm{CN}$ addition but its decrease was not very important before the treatment for the composites with 1-5 wt\% CN (Figure 4).

Surprisingly, higher elongation at break was observed after the thermal treatment in the case of PA11 and PA11/CN1 compared to untreated samples and drastic decrease after the addition of higher amount of CN. Studying the stress-strain curves of PA11 and PA11/CN5 before and after the thermal treatment, a completely different behavior was observed (Figure 5). A transition from a quasi-ductile behavior (before treatment) to one involving necking and cold drawing 


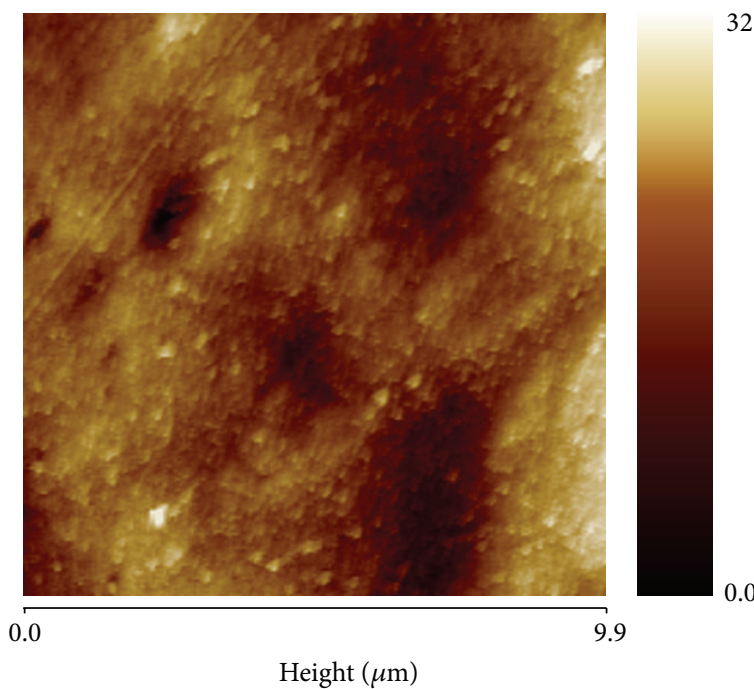

(a)

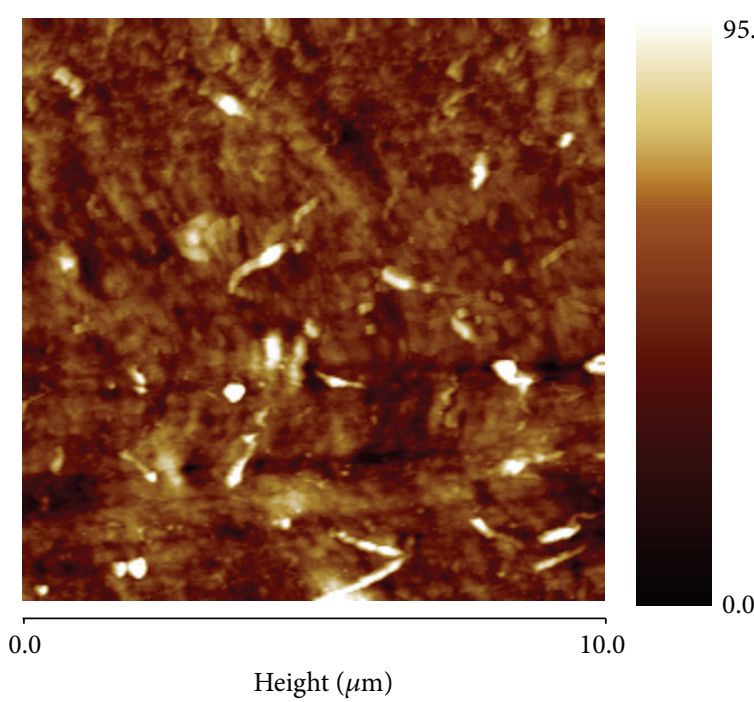

(c)
32.5

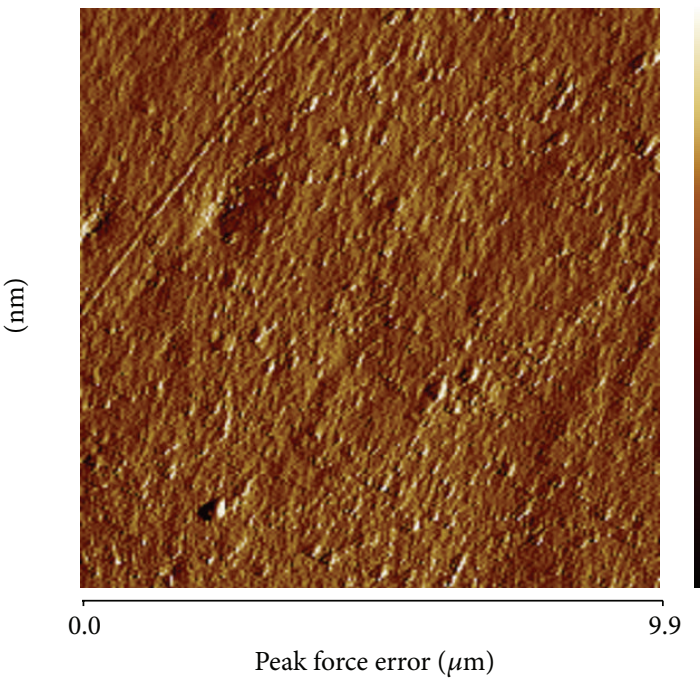

(b)

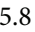

坖
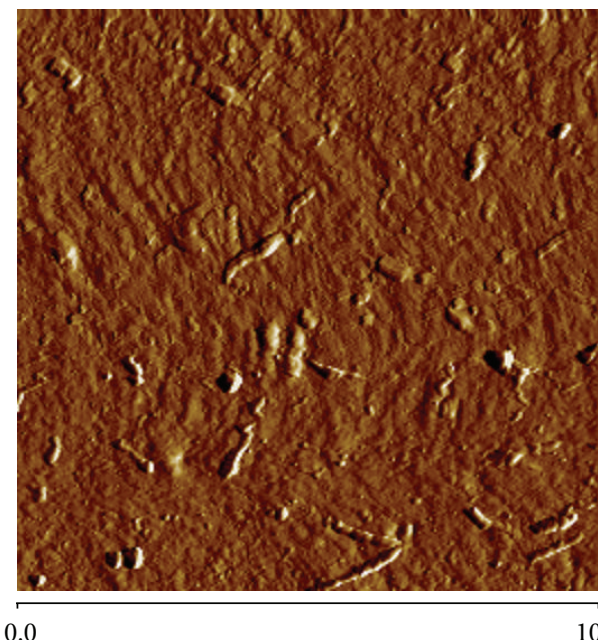

Peak force error $(\mu \mathrm{m})$

(d)

Figure 6: Height and PF error images of PA11 ((a) and (b)) and PA11/CN5 ((c) and (d)).

(after the treatment) was observed in the case of PA11. Quasiductile behavior was observed for PA/CN5 before and after the thermal treatment but the remarkable increase of both strength and stiffness for this composite after the treatment is worth noting. Geometrical reduction in cross-sectional area on the formation of a neck was observed only for PA1lt specimens.

All the above-mentioned differences between treated and untreated samples, pointed out by static and dynamic mechanical tests, could be determined by morphological changes. To emphasize these changes AFM investigation was undertaken on both treated and untreated films.

3.4. Morphological Characterization of PA11 and Nanocomposites by PF QNM. Topographic and PF error images of PA11 and PA11/CN5, scan area $10 \mu \mathrm{m} \times 10 \mu \mathrm{m}$, are shown in Figures 6(a) $-6(d)$.

Deeper analysis of these images emphasizes brighter domains alternating with darker narrow domains on the surface of both PA11 and PA11/CN5 samples. The brighter domains, 200-350 $\mathrm{nm}$ in width, can be ascribed to bundles of semicrystalline stacks separated by darker amorphous domains. This is a common trend in semicrystalline polymers containing both crystalline and amorphous phases, as specified in [14].

A spectacular change in the surface aspect of PA11 and nanocomposites was detected after the treatment (Figures $7(\mathrm{a})-7(\mathrm{~h}))$. Spherulitic morphology spreading uniformly over the whole surface was observed in all samples, neat PA11 and nanocomposites. The diameter of the spherulites 


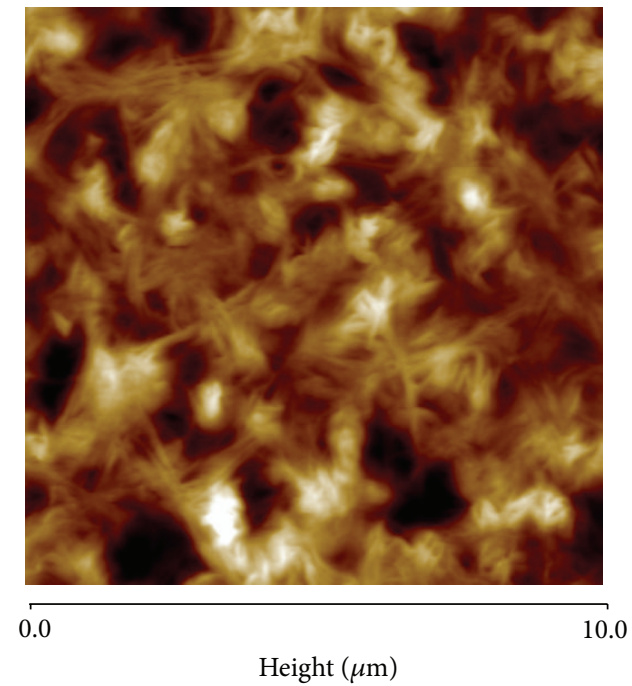

(a)

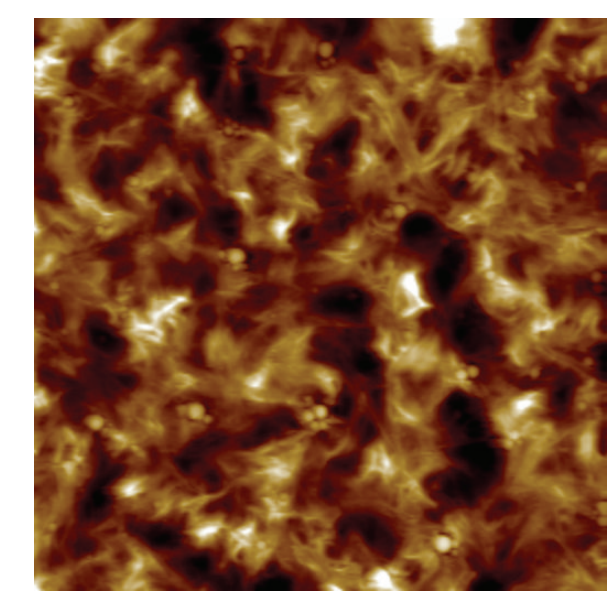

0.0

Height $(\mu \mathrm{m})$

(c)

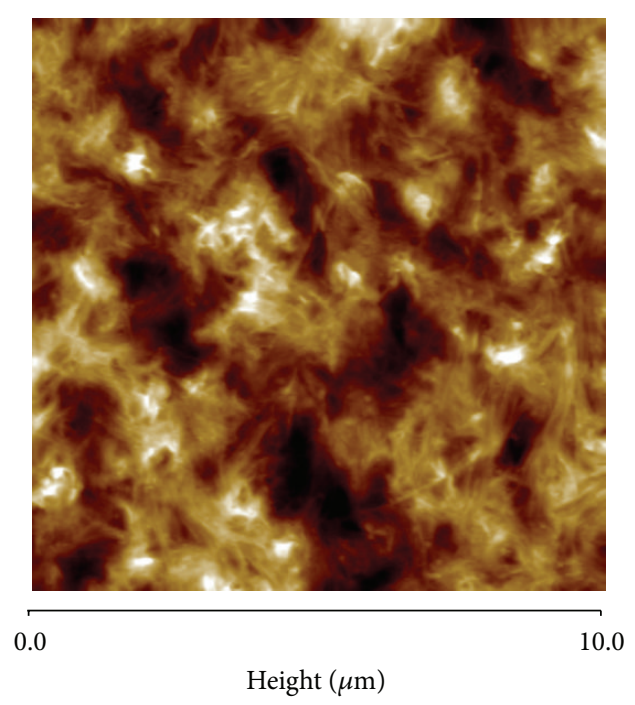

(e)
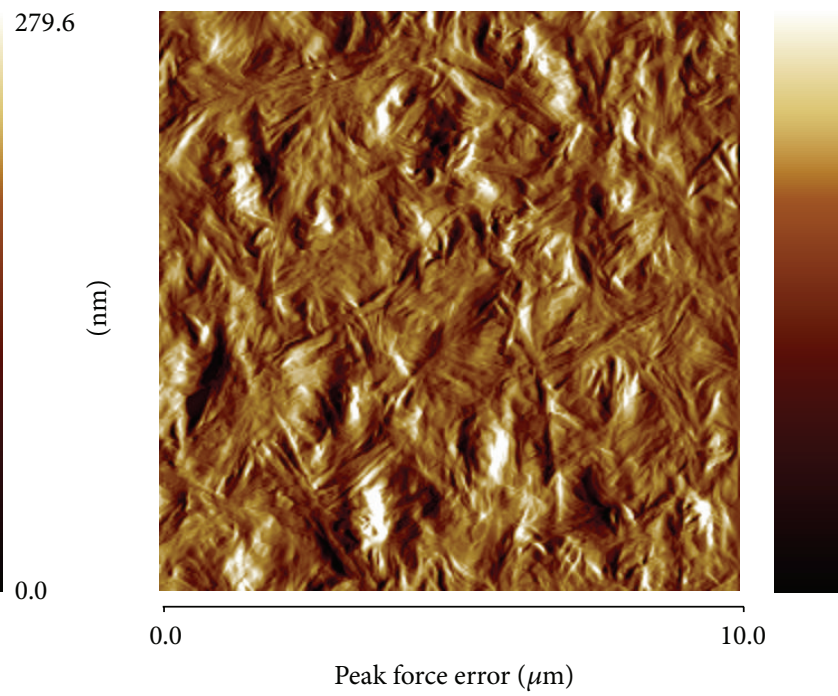

81.9

ב্ভ

(b)
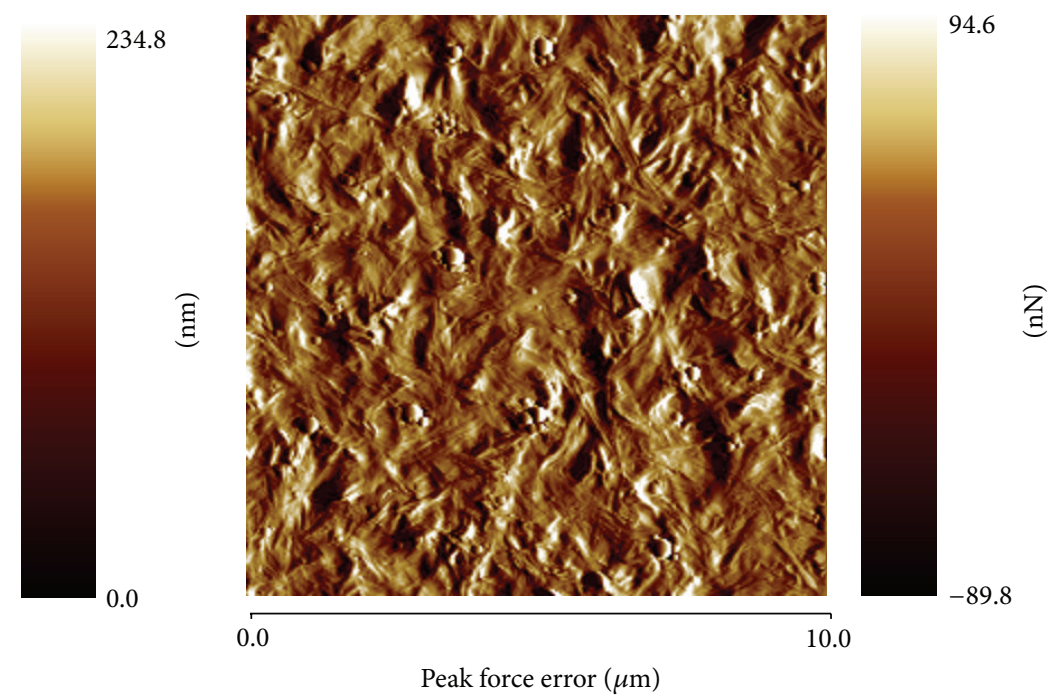

(d)

247.8

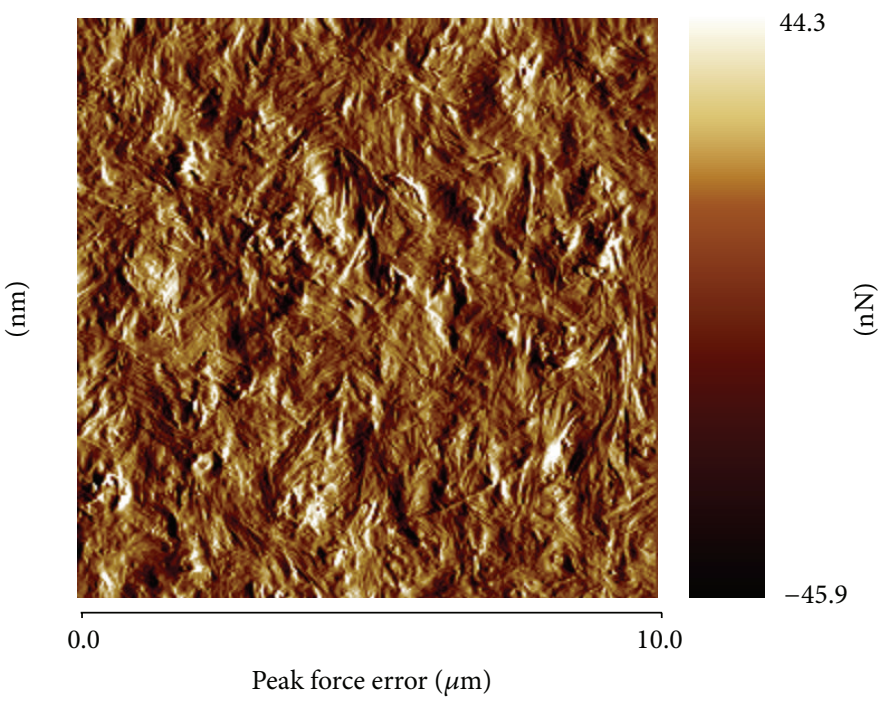

(f)

Figure 7: Continued. 


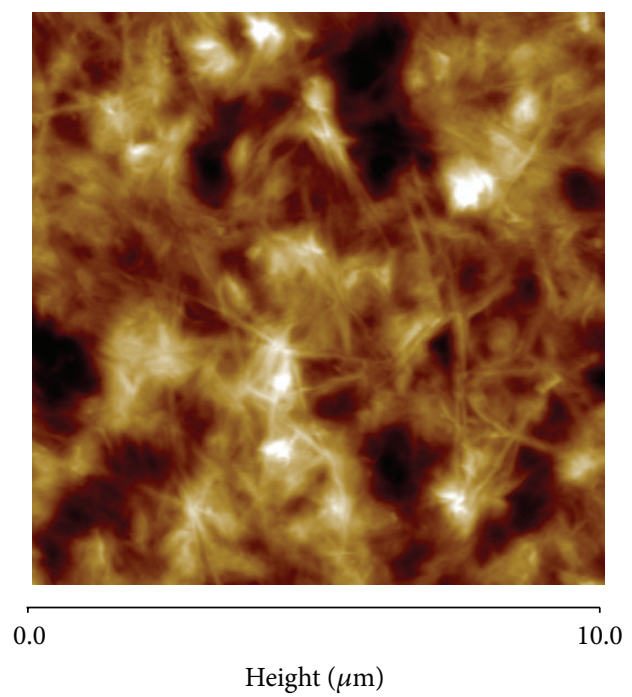

(g)

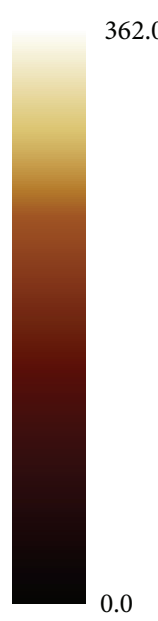

0.0
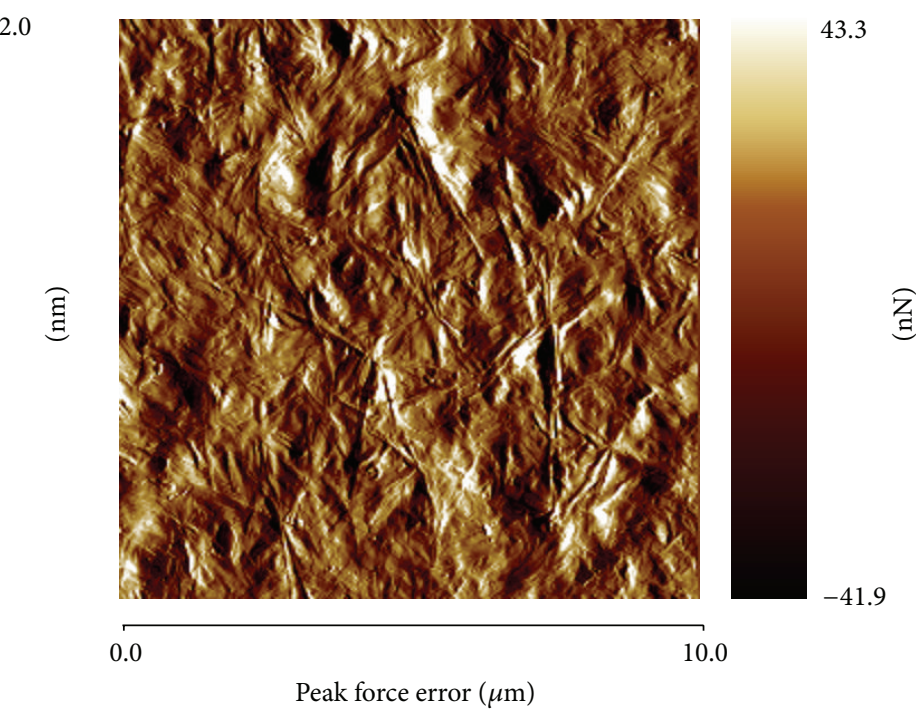

(h)

Figure 7: Height and PF error images of PAll ((a) and (b)), PA11/CN1 ((c) and (d)), PAll/CN5 ((e) and (f)), and PA11/CN8 ((g) and (h)) after the treatment.

ranges from $2 \mu \mathrm{m}$ to almost $4 \mu \mathrm{m}$, similar with other AFM observations in the case of a PA6 film [24].

Detailed AFM images of PAll showed that the spherulites exhibit radial lamellar bundles of 100-200 nm width (Figures $8(a)-8(d)$ ). Both stacked lamellae in radial direction and branched ones can be observed in the detailed images, showing different stages of growth during crystallization.

AFM images from Figures 7 and 8 suggest increased crystallinity in the samples after thermal treatment. This could explain the increase of both tensile strength and modulus for treated samples compared to untreated ones. The change in crystallinity was verified by XRD analysis for the reference and nanocomposites.

3.5. XRD Analysis. X-ray diffraction patterns of PA11 (Figure 9) show the three characteristic peaks at $2 \theta 20.3^{\circ}$, $23.2^{\circ}$, and $7.3^{\circ}$. They correspond to the (100), (110)/(010), and (001) reflections of the $\alpha^{\prime}$ form (interplanar spacings $d_{100} 4.37 \AA, d_{110 / 010} 3.83 \AA$, and $d_{001} 12.10 \AA$ ), similar to other observations [25]. The two main diffraction peaks correspond to the projected interchain distance between the hydrogen-bonded chains and to the intersheet distance, respectively [26]. Nanocomposites with different content of $\mathrm{CN}$ show similar diffraction patterns as PA11 and the same $\alpha^{\prime}$ crystal structure. However, a shift with $0.1^{\circ}-0.2^{\circ}$ of the $(110) /(010)$ peak to a lower angle was observed for all nanocomposites compared to PA11. This emphasizes a larger spacing between hydrogen-bonded sheets and, therefore, a slightly lower perfection of the crystalline structure of polyamide 11 induced by $\mathrm{CN}$ addition.

Important changes were observed after the treatment in the diffraction patterns of PAll (Figure 10(a)).

Although the same triclinic $\alpha^{\prime}$ structure was detected before and after thermal treatment, the significant increase of the intensity of $(110) /(010)$ reflection indicates higher crystallinity and much better organization of PA1l sheets. The slight shift towards higher angle, observed for the main peak, also results from the higher order and perfection of the crystals. Nanocomposites did not show the same behavior after the treatment (Figures 10(b) and 10(c)). The diffraction patterns are very similar to that before the treatment with the difference of higher intensity of (001) and (100) reflections. However, the diffraction peaks are rather broad and overlapped and the fitting of experimental data was performed to obtain additional information (Figure 11).

A new small peak at $2 \theta$ of about 21.6 (4.1 $\AA$ ) was detected in all samples after the decomposition of XRD patterns. This reflection is the characteristic of pseudohexagonal $\gamma$ form of PA11 [26]. Polyamide 11 shows polymorphism with five different crystalline forms, the $\alpha$ and $\alpha^{\prime}$ forms showing a triclinic structure and $\delta, \delta^{\prime}$, or $\gamma$ showing a pseudohexagonal one $[26,27]$. Interestingly, this peak has higher intensity in neat polyamide before the treatment than after the treatment (Figure 11). The $\gamma$ form of PAll is metastable [27] and, therefore, it may transform in more stable $\alpha^{\prime}$ form after the treatment. It is worth noting that the peak of pseudohexagonal $\gamma$ form also appeared in nanocomposites but its intensity did not significantly change after the treatment. This could be caused by the strong interactions between amide and hydroxyl groups of $\mathrm{CN}$, which hinder the polymorphic transformation in a more stable form. However, the proportion of $\gamma$ form in nanocomposites is small (under 20\%) and its influence on their mechanical behavior is not, probably, significant. On the other hand, an important increase of crystallinity was observed in PA1l after the treatment, from $57 \%$ to $65 \%$, which could explain the improvement observed in the mechanical behavior of the reference. Although the relative degree of crystallinity was slightly lower for nanocomposites 


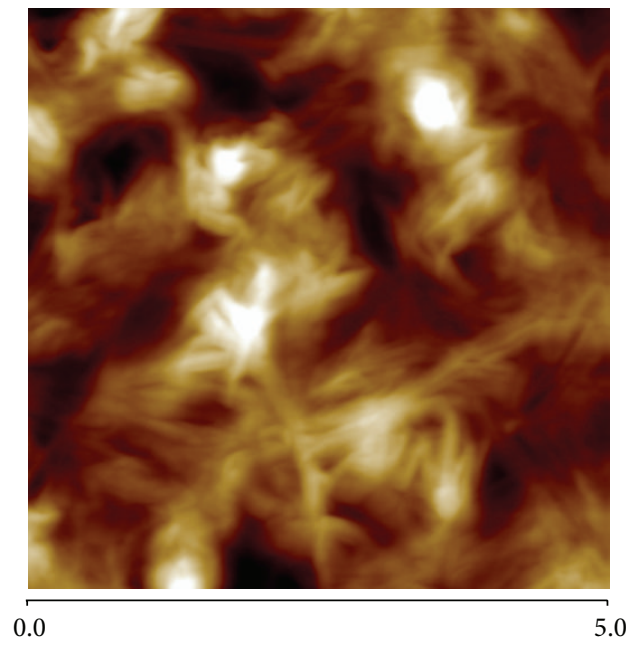

Height $(\mu \mathrm{m})$

(a)

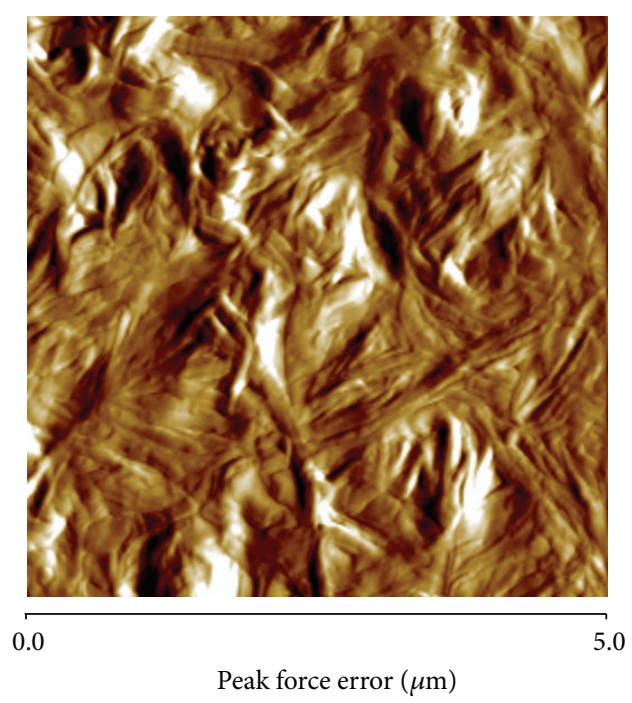

(c)
198.2

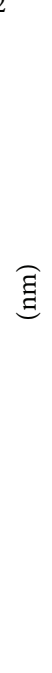

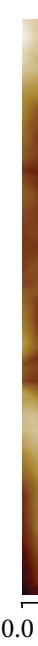

0.0

(b)

68.7

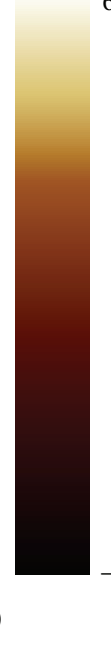

$-70.1$

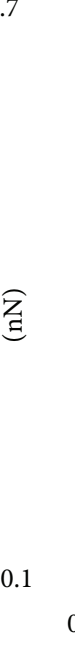

20.2

FIgURE 8: Detailed height and PF error images of PA11 after the treatment.

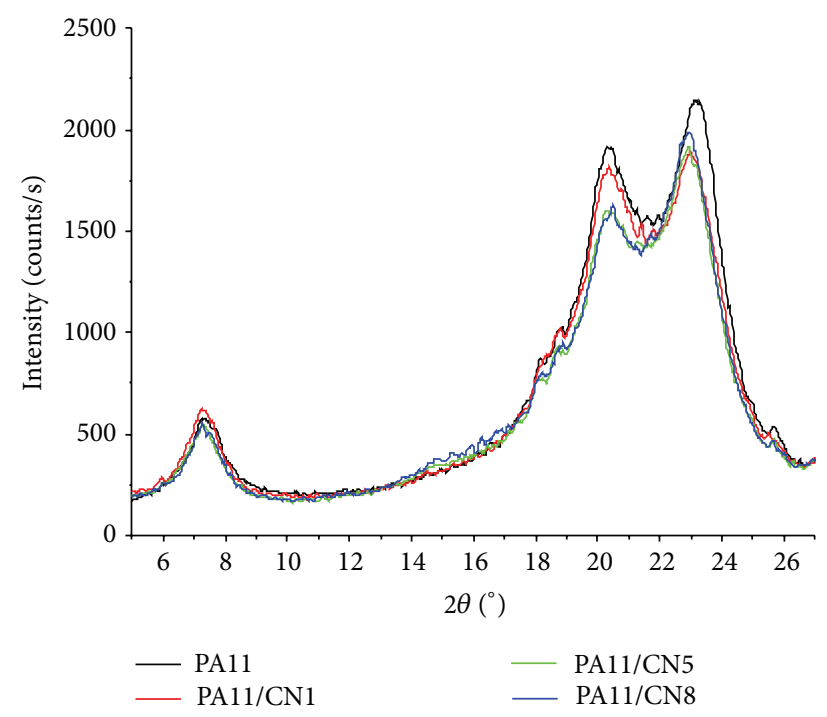

FIGURE 9: XRD patterns of PA11 and nanocomposites (before the treatment). 


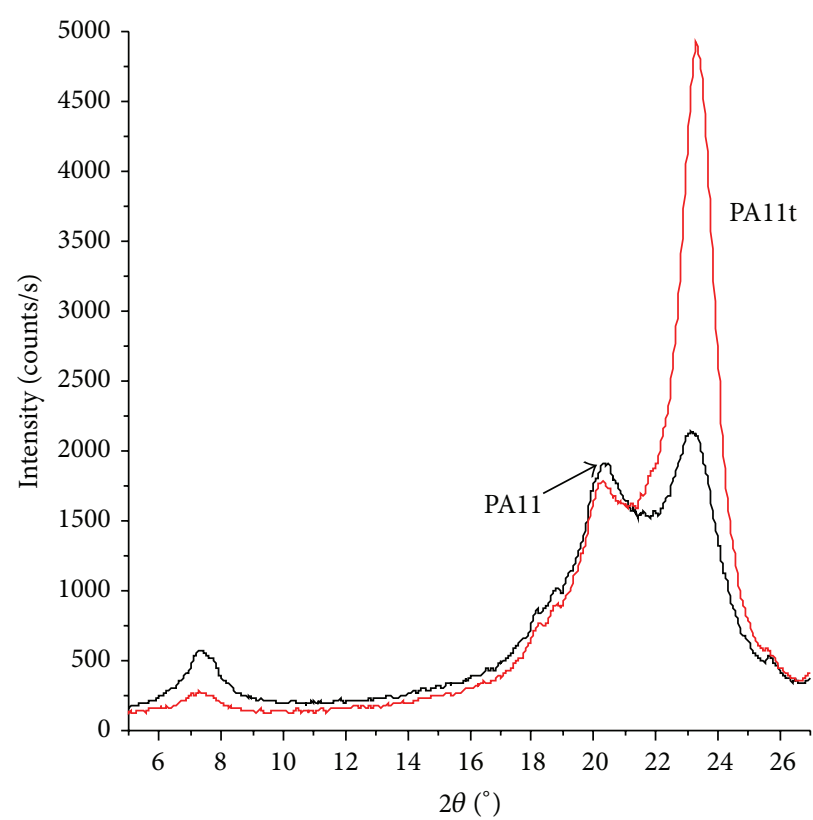

(a)

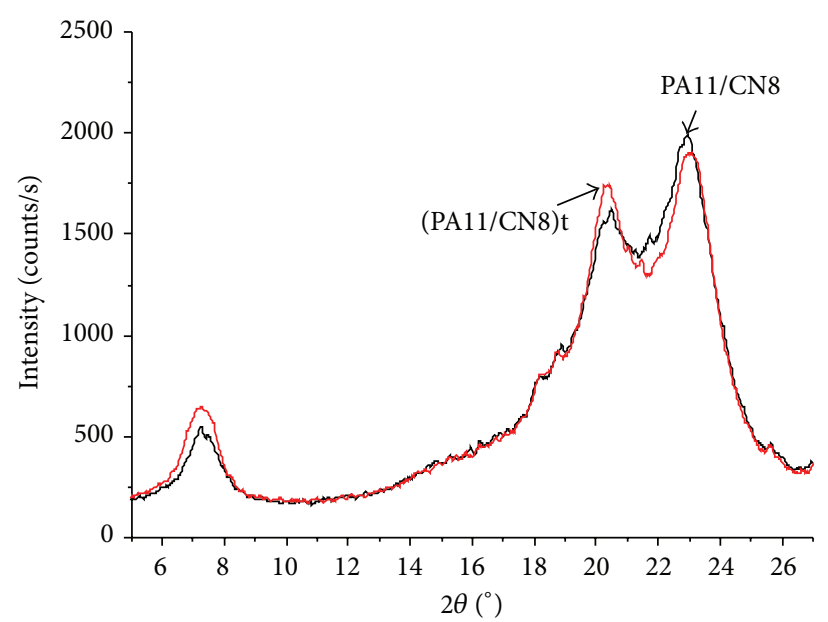

(c)

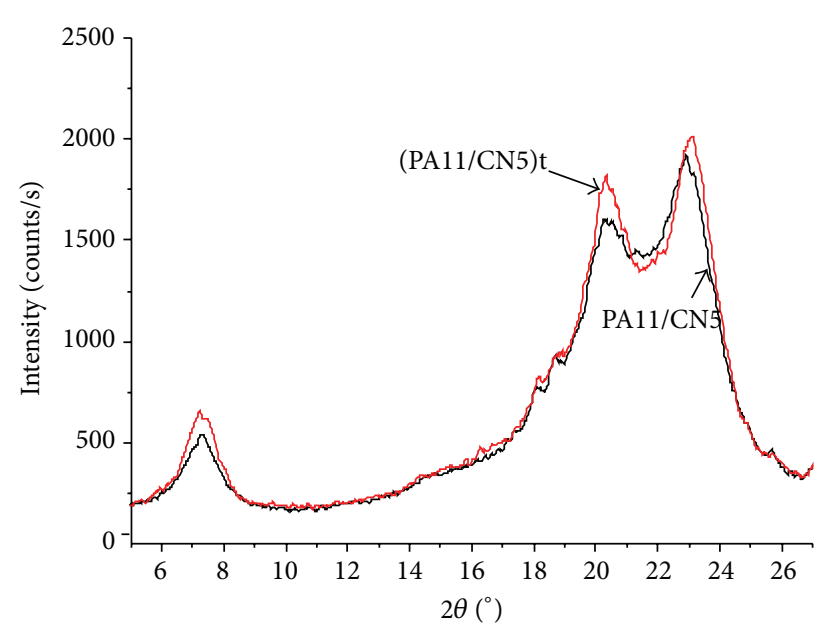

(b)

FIgURE 10: XRD patterns of PA11 (a), PA11/CN5 (b), and PA11/CN8 (c) before (black line) and after (red line) the treatment.

compared to PAll before the treatment, a similar increase of crystallinity was detected in nanocomposites after the treatment, from $55 \%$ to $64 \%$ for PA11/CN5 and from $55 \%$ to $63 \%$ for PA11/CN8. Morphological changes pointed out by XRD analysis are consistent with AFM results and confirm the influence of the crystallinity on the mechanical behavior of PA11 and nanocomposites.

\section{Conclusions}

Thermal treatment has a significant impact on the morphology and mechanical properties of PAll and nanocomposite films containing different amount of CN. Slightly higher $E^{\prime}$ values were obtained for nanocomposites compared to the matrix before the treatment, but a noticeable increase of storage modulus of both PA1l and nanocomposites and visible difference between nanocomposites and neat PA11 after the treatment. Higher $T_{g}$ values were obtained for nanocomposites compared to neat PAll after the treatment, highlighting strong interaction between $\mathrm{CN}$ and the matrix. A relatively steady increase of Young's modulus with $\mathrm{CN}$ concentration and a small increase of tensile strength were observed before the treatment but a significant increase of tensile strength and modulus for nanocomposites with 1$5 \mathrm{wt} \% \mathrm{CN}$ after the treatment. The best mechanical properties were shown by treated PA11/CN5, with an increase of Young's modulus with more than $40 \%$ and of tensile strength with $35 \%$ compared to the matrix. Surprisingly, PAll showed higher elongation at break after the thermal treatment and a transition from a quasi-ductile behavior (before treatment) to one involving necking and cold drawing (after treatment). This behavior was not observed in the case of nanocomposites 


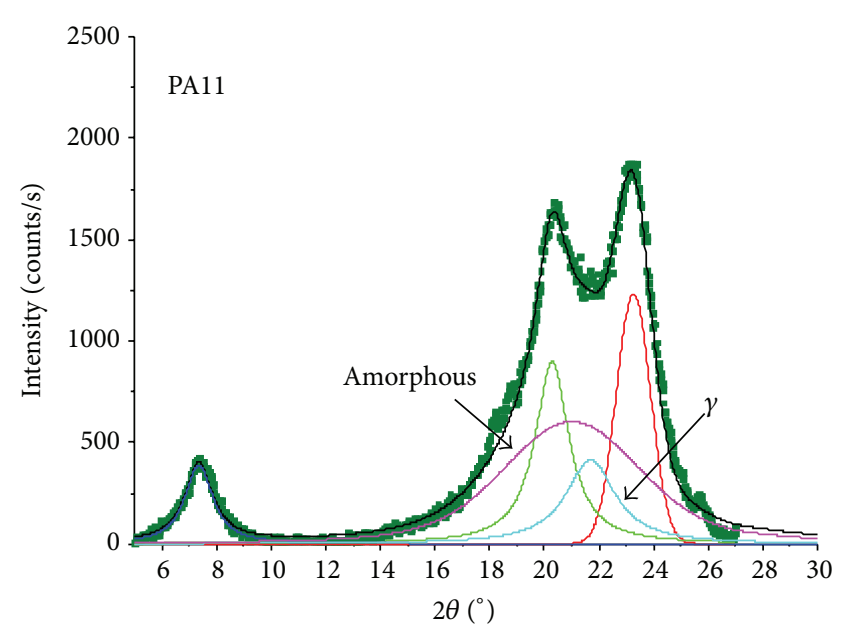

(a)

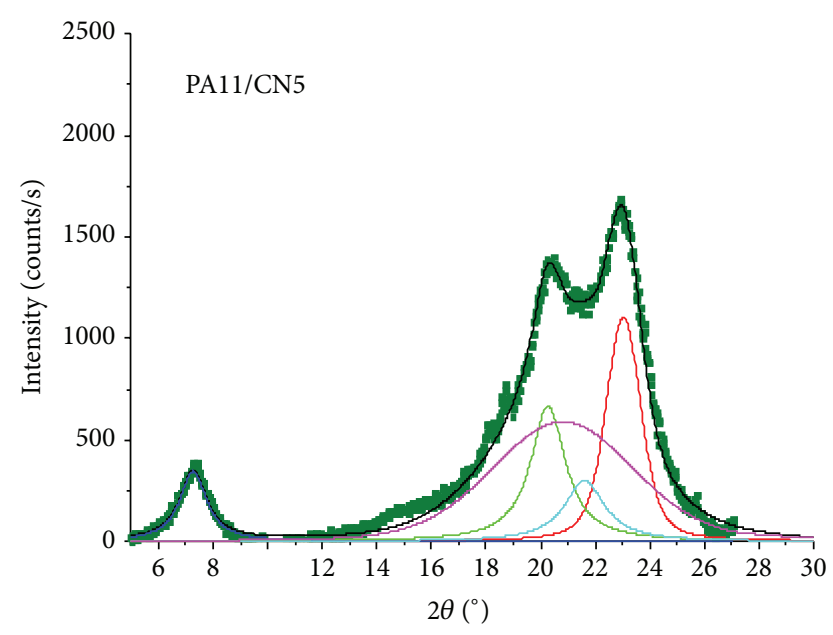

(c)

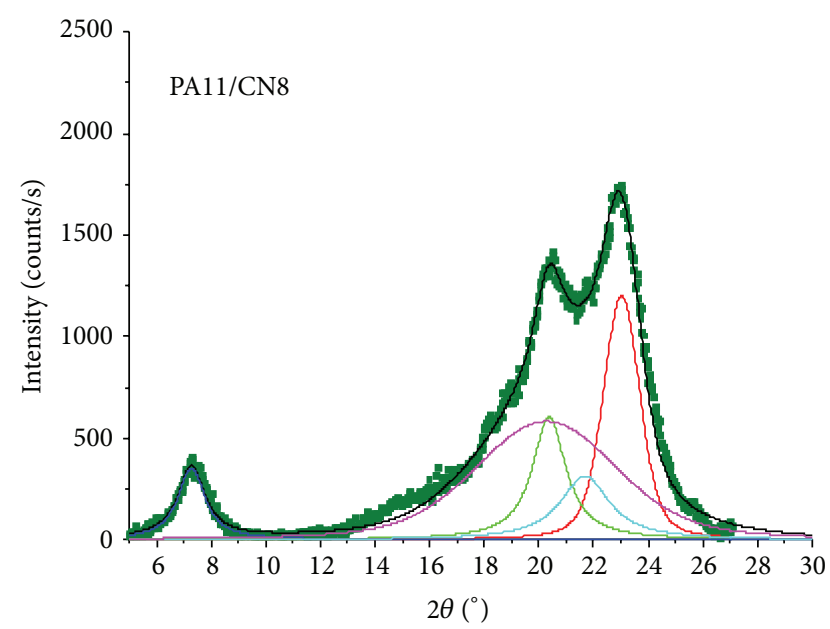

(e)

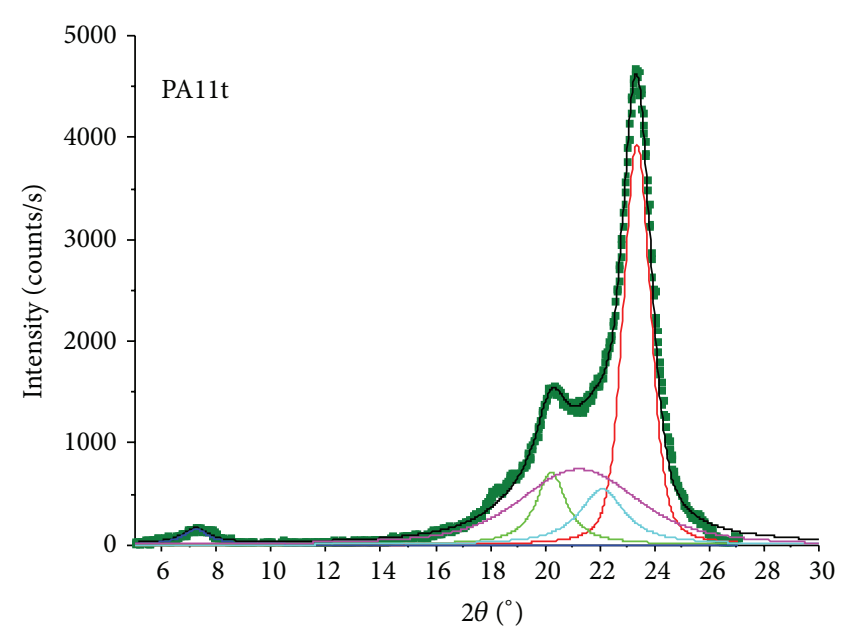

(b)

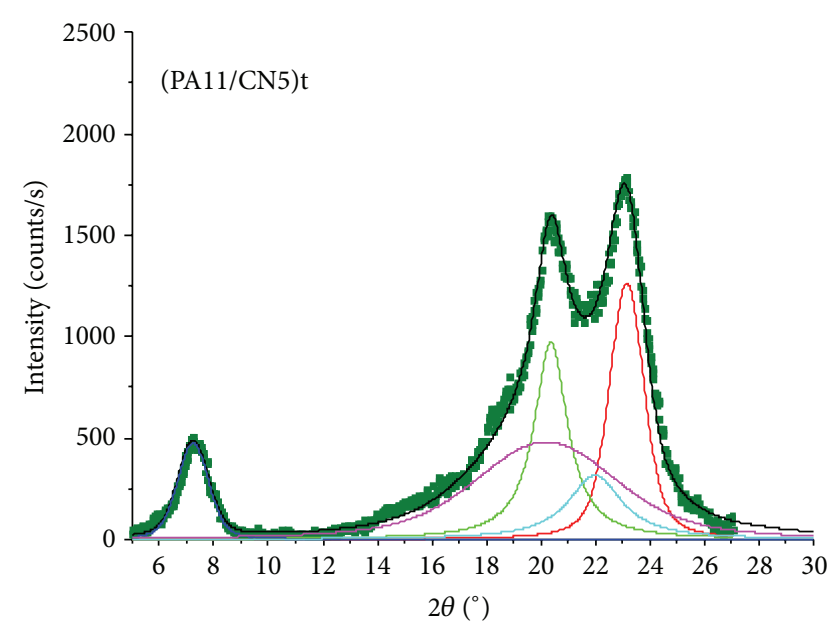

(d)

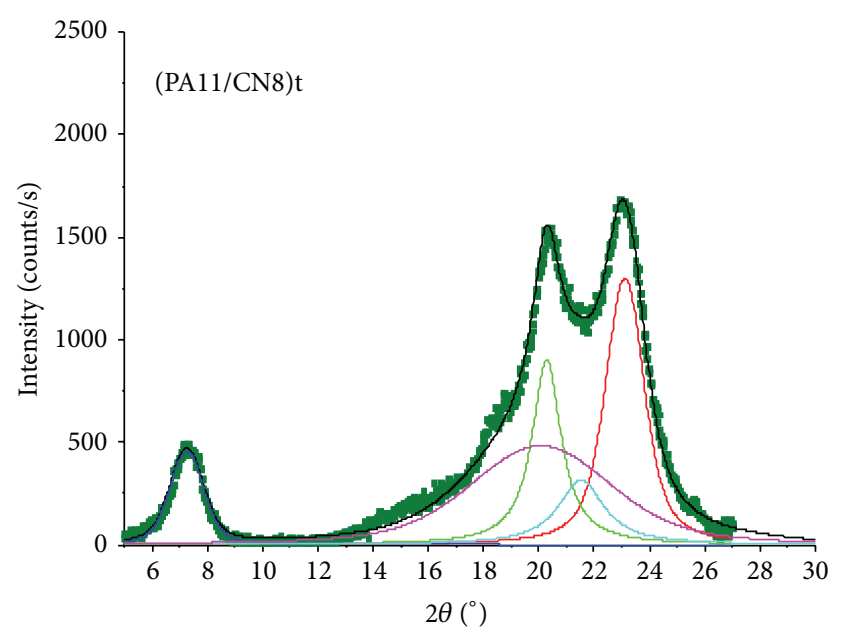

(f)

FIgURE 11: Decomposition of X-ray patterns of PA11, PA11/CN5, and PA11/CN8 before and after the treatment. 
probably because of $\mathrm{CN}$ which restrict the mobility. Important morphological changes were highlighted by AFM after the treatment on the surface of PA11 and nanocomposites films and a transition from lamellar stack morphology to one involving spherulites. Both the morphological changes emphasized by AFM and the increase of crystallinity pointed out by XRD explained the different mechanical behavior observed in tensile tests and DMA. Thermal treatment has proved a valuable method for improving the mechanical properties of PA11/CN composites.

\section{Conflict of Interests}

The authors declare that there is no conflict of interests regarding the publication of this paper.

\section{References}

[1] M. N. Belgacem and A. Gandini, Monomers, Polymers and Composites from Renewable Resources, Elsevier, Amsterdam, The Netherlands, 1st edition, 2008.

[2] A. S. Singha and V. K. Thakur, Green Polymer Materials, Studium Press LLC, Houston, Tex, USA, 2012.

[3] D. M. Panaitescu, Z. Vuluga, M. Ghiurea, M. Iorga, C. Nicolae, and R. Gabor, "Influence of compatibilizing system on morphology, thermal and mechanical properties of high flow polypropylene reinforced with short hempfibers," Composites Part B: Engineering, vol. 69, pp. 286-295, 2015.

[4] A. R. Kakroodi, S. Cheng, M. Sain, and A. Asiri, "Mechanical, thermal, and morphological properties of nanocomposites based on polyvinyl alcohol and cellulose nanofiber from Aloe vera Rind," Journal of Nanomaterials, vol. 2014, Article ID 903498, 7 pages, 2014.

[5] V. K. Thakur and A. S. Singha, Biomass-Based Biocomposites, Smithers Rapra, Shawbury, UK, 2013.

[6] A. N. Frone, S. Berlioz, J.-F. Chailan, and D. M. Panaitescu, "Morphology and thermal properties of PLA-cellulose nanofibers composites," Carbohydrate Polymers, vol. 91, no. 1, pp. 377-384, 2013.

[7] T. Liu, K. P. Lim, W. C. Tjiu, K. P. Pramoda, and Z.-K. Chen, "Preparation and characterization of nylon 11/organoclay nanocomposites," Polymer, vol. 44, no. 12, pp. 3529-3535, 2003.

[8] G. Stoclet, M. Sclavons, and J. Devaux, "Relations between structure and property of polyamide 11 nanocomposites based on raw clays elaborated by water-assisted extrusion," Journal of Applied Polymer Science, vol. 127, no. 6, pp. 4809-4824, 2013.

[9] S. Huang, M. Wang, T. Liu et al., "Morphology, thermal, and rheological behavior of nylon 11/multi-walled carbon nanotube nanocomposites prepared by melt compounding," Polymer Engineering and Science, vol. 49, no. 6, pp. 1063-1068, 2009.

[10] X. Zhang, G. Yang, and J. Lin, "Crystallization behavior of nylon 11/montmorillonite nanocomposites under annealing," Journal of Applied Polymer Science, vol. 102, no. 6, pp. 5483-5489, 2006.

[11] Y. Hu, L. Shen, H. Yang et al., "Nanoindentation studies on Nylon 11/clay nanocomposites," Polymer Testing, vol. 25, no. 4, pp. 492-497, 2006.

[12] G. Mago, D. M. Kalyon, and F. T. Fisher, "Nanocomposites of polyamide-11 and carbon nanostructures: development of microstructure and ultimate properties following solution processing," Journal of Polymer Science, Part B: Polymer Physics, vol. 49, no. 18, pp. 1311-1321, 2011.
[13] T. D. Fornes and D. R. Paul, "Structure and properties of nanocomposites based on nylon-11 and -12 compared with those based on nylon-6," Macromolecules, vol. 37, no. 20, pp. 76987709, 2004.

[14] D. M. Panaitescu, A. N. Frone, and C. Nicolae, "Micro- and nano-mechanical characterization of polyamide 11 and its composites containing cellulose nanofibers," European Polymer Journal, vol. 49, no. 12, pp. 3857-3866, 2013.

[15] A. Dufresne, Nanocellulose: From Nature to High Performance Tailored Materials, Walter de Gruyter, Berlin, Germany, 1st edition, 2012.

[16] M. A. Hubbe, O. J. Rojas, L. A. Lucia, and M. Sain, "Cellulosic nanocomposites: a review," BioResources, vol. 3, no. 3, pp. 929980, 2008.

[17] D. M. Panaitescu, D. Donescu, C. Bercu, D. M. Vuluga, M. Iorga, and M. Ghiurea, "Polymer composites with cellulose microfibrils," Polymer Engineering and Science, vol. 47, no. 8, pp. 1228 1234, 2007.

[18] D. M. Panaitescu, P. V. Notingher, M. Ghiurea et al., "Properties of composite materials from polyethylene and cellulose microfibrils," Journal of Optoelectronics and Advanced Materials, vol. 9, no. 8, pp. 2526-2528, 2007.

[19] S. H. Lee, Y. Teramoto, and T. Endo, "Cellulose nanofiberreinforced polycaprolactone/polypropylene hybrid nanocomposite," Composites Part A, vol. 42, pp. 151-156, 2011.

[20] Q. Zhang, Z. Mo, S. Liu, and H. Zhang, "Influence of annealing on structure of Nylon 11," Macromolecules, vol. 33, no. 16, pp. 5999-6005, 2000.

[21] D. M. Panaitescu, A. N. Frone, and I. C. Spataru, "Effect of nanosilica on the morphology of polyethylene investigated by AFM," Composites Science and Technology, vol. 74, pp. 131-138, 2013.

[22] B. Imre, D. Bedő, A. Domján, P. Schön, G. J. Vancso, and B. Pukánszky, "Structure, properties and interfacial interactions in poly(lactic acid)/polyurethane blends prepared by reactive processing," European Polymer Journal, vol. 49, no. 10, pp. 31043113, 2013.

[23] Y. Luo, J. Zhang, X. Li, C. Liao, and X. Li, "The cellulose nanofibers for optoelectronic conversion and energy storage," Journal of Nanomaterials, vol. 2014, Article ID 654512, 13 pages, 2014.

[24] V. Ferreiro, Y. Pennec, R. Séguéla, and G. Coulon, "Shear banding in polyamide 6 films as revealed by atomic force microscopy," Polymer, vol. 41, no. 4, pp. 1561-1569, 2000.

[25] P. Ricou, E. Pinel, and N. Juhasz, “Temperature experiment for improved accuracy in the calculation of polyamide-11 crystallinity by X-ray diffraction," Advances in X-Ray Analysis, vol. 48, pp. 170-175, 2005.

[26] S. S. Nair, C. Ramesh, and K. Tashiro, "Crystalline phases in nylon-11: studies using HTWAXS and HTFTIR," Macromolecules, vol. 39, no. 8, pp. 2841-2848, 2006.

[27] G. Zhang, Y. Li, and D. Yan, "Polymorphism in nylon-11/montmorillonite nanocomposite," Journal of Polymer Science, Part B: Polymer Physics, vol. 42, no. 2, pp. 253-259, 2004. 

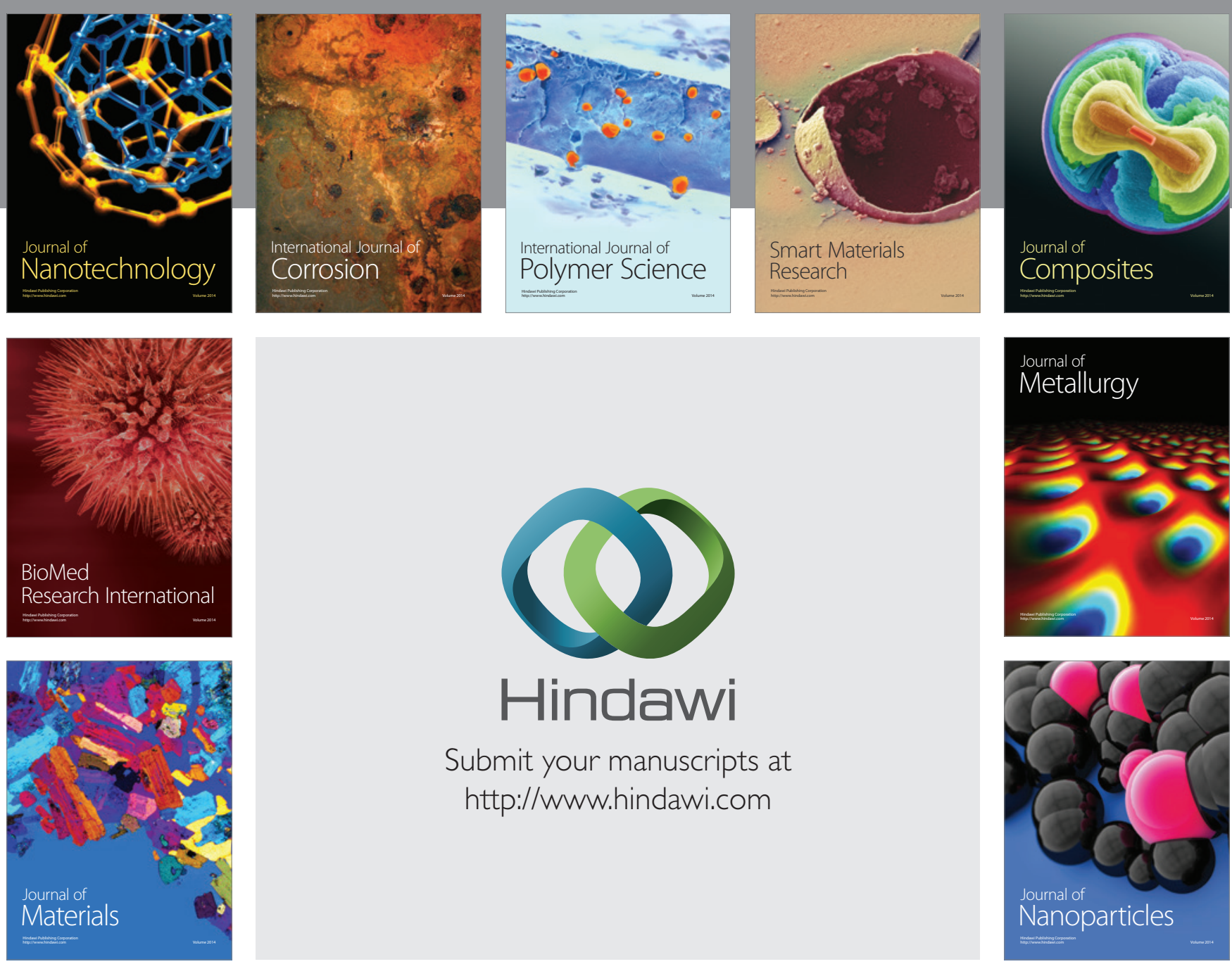

Submit your manuscripts at http://www.hindawi.com
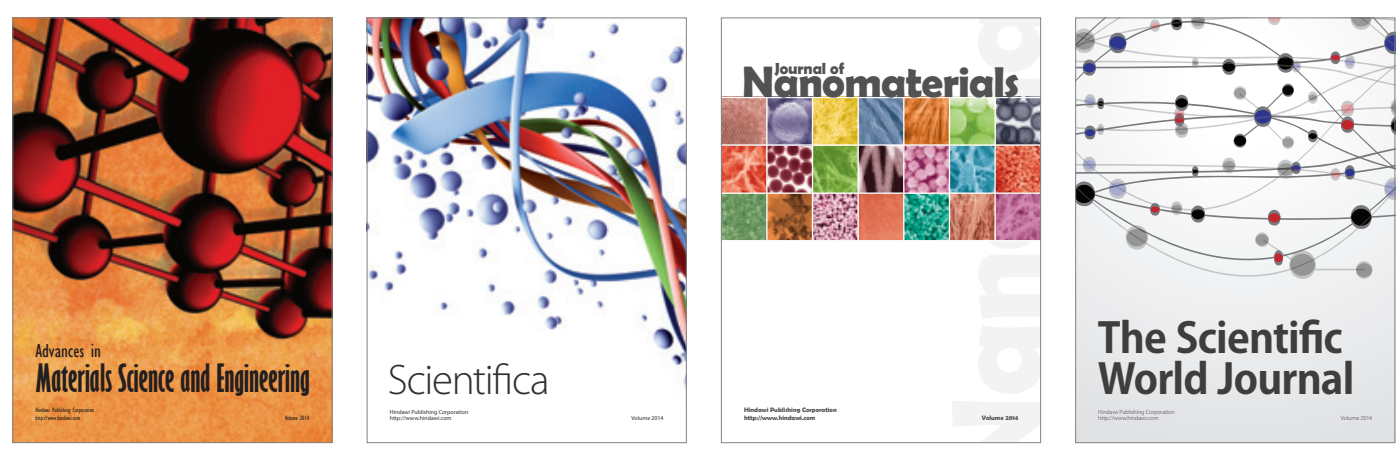

\section{The Scientific World Journal}
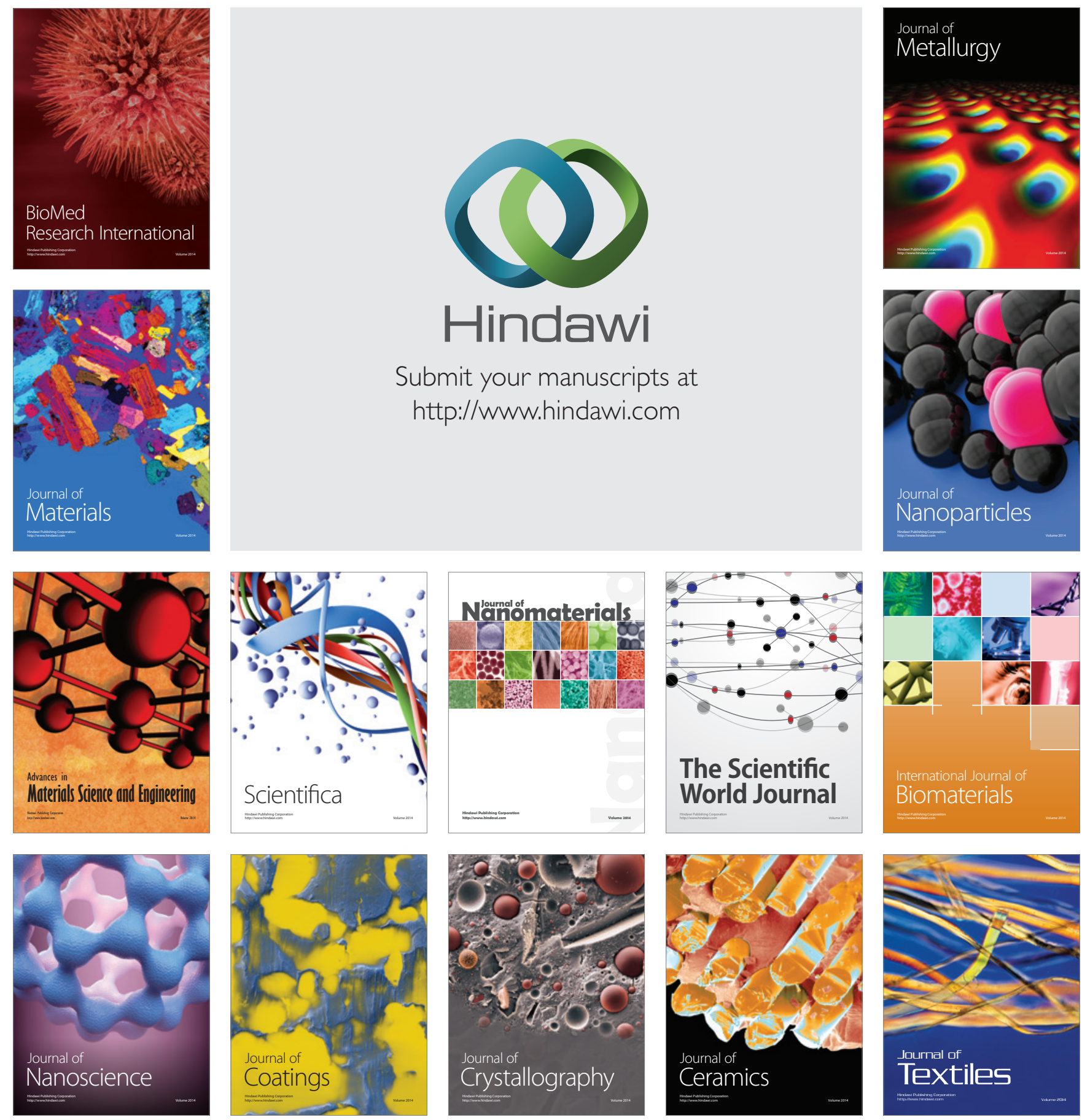